\title{
Bearing resistance property of diameter-expanded anchorage in sandy ground
}

\author{
Toshikazu Sawamatsu, ${ }^{1,}$, Takehiko $\mathrm{Nitta}^{1}$, Hiroaki Miyatake ${ }^{1}$, and Masahide Otsubo ${ }^{2}$ \\ ${ }^{1}$ Public Works Research Institute, Tsukuba, Japan \\ ${ }^{2}$ The University of Tokyo, Institute of Industrial Science, Tokyo, Japan
}

\begin{abstract}
Based on a past centrifugal model test and complementary discrete element method (DEM) simulation, this paper provides insights into bearing resistance of diameter-expanded anchorage with its anchor body expanded. In the centrifugal model test, an anchor body model set at a depth of $100 \mathrm{~mm}$ and a diameter of $27 \mathrm{~mm}$ in sand was pulled horizontally in a centrifugal acceleration of $30 \mathrm{G}$. The behaviour of the model ground during pulling was portrayed through the DEM modelling. Spherical particle and non-spherical particle composed of two spherical particles connected rigidly were used as analogues of soil particles in the simulation. The simulation result of spherical particle with inter-particle friction coefficient of 0.5 was similar to the ground deformation and the pull-out resistance obtained from the experiment.
\end{abstract}

\section{Introduction}

Diameter-expanded anchorage is a ground anchorage which expands an anchor body part as compared with a free length part, as shown in Figure1. The circumferential friction area per unit length of the anchor body is larger than that of conventional anchorage, and the large anchor body adds bearing resistance on its top surface. Therefore, the diameter-expanded anchorage can make a large pullout resistance even with a short anchor body length in a soft ground.

In order to design the pull-out resistance of the diameter-expanded anchorage with careful consideration of its mechanical property, it is necessary to evaluate the bearing resistance which is not considered in the conventional anchorage. According to the centrifugal model tests using expanded-diameter anchorage by Sawamatsu et al. [1], the pull-out resistance of expandeddiameter anchor can be separated into the frictional component and the bearing resistance component. Regarding the bearing resistance, much effort has been put into developing a design method for ultimate pull-out resistance of belled piers and mushroom foundations. Model experiments in $1 \mathrm{G}$ field [2-3], centrifugal model tests [1, 4-5]) and field tests [6] have been extensively reported in the literature. In the majority of these earlier studies, a failure mechanism was assumed, and the uplift capacity was then determined by analytical methods such as limit equilibrium, cavity expansion, and limit analysis. In such a procedure, it is important to assume proper mathematical failure mechanism based on the observed ground deformation. Recent theoretical studies by finite element analysis (FEM) have been reported [7-8].

The expanded-diameter anchorage has an advantage that the anchor free length, and thus drilling length can be shortened. However, a soil retaining wall near the anchor body may inhibit a ground deformation during pulling the anchorage and affect its bearing resistance. Most of the past research is based on the condition where ground deformation due to bearing resistance is not influenced by boundary, e.g. earth retaining walls. Although the bearing resistance of the anchor installed near a slope has been verified, to our knowledge, no research has been reported on the distance between the soil retaining wall and the anchor body.

This paper presents the DEM simulation results on the pull-out of diameter-expanded anchorage focused on the distance between the anchor body and the retaining wall. First, past centrifugal model tests [1] without retaining walls were simulated; the ground deformation and pullout load obtained from the simulations and the model tests were compared and particle characteristics suitable for the simulation were evaluated. Next, the simulations were performed at the various distances between the anchor body and the retaining wall, and the ground behaviour during pulling was analysed.

\section{Discrete element method}

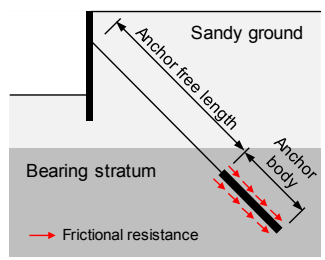

a) Conventional ground anchorage

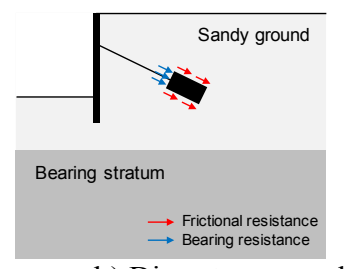

b) Diameter-expanded anchorage
Fig. 1. Type of ground anchorage.

\footnotetext{
* Corresponding author: t-sawamatsu@pwri.go.jp
} 


\subsection{Outline of past centrifugal model tests}

In the DEM analyses, we focused on the centrifugal model tests conducted by Sawamatsu et al. [1]. Figure 2a illustrates a setup of the centrifugal model tests. Two types of tests: Test 1 and Test 2, were conducted. In Test 1 , in order to examine the deformation behaviour of the ground subjected to pull-out of the diameter-expanded anchorage, the ground behaviour of a vertical plane passing through the axis of the anchorage was reproduced on a glass wall of a soil chamber. In Test 2, a circular anchor plate embedded in ground was pulled. In a $30 \mathrm{G}$ centrifugal acceleration field, anchorage models of $27 \mathrm{~mm}$ diameter (i.e. diameter of prototype was $0.8 \mathrm{~m}$ ) were pulled at an angle of anchor insertion $\alpha$ of $0^{\circ}$ : horizontal direction. The anchorage model was made of stainless steel. Air-dried Toyoura sand which was clean, fine and fairly uniform, having its soil particle density $\rho s$ of 2.64 $\mathrm{g} / \mathrm{cm}^{3}$, uniformity coefficient $D_{60} / D_{10}$ of 1.3 , mean diameter $D_{50}$ of $0.2 \mathrm{~mm}$, maximum void ratio $e_{\max }$ of 0.977 and minimum void ratio $e_{\min }$ of 0.605 was used in all tests. The model ground was prepared by air pluviation method with a sand hopper. In the $30 \mathrm{G}$ centrifugal acceleration field, the anchor model was pulled with a screw-jack under displacement control at a rate of $0.05 \mathrm{~mm} / \mathrm{s}$ in a horizontal direction. The pull-out force was measured using a load cell attached between the anchor model and the screw-jack. In Test 1, in order to observe development of ground deformation during pull-out of the anchor model, thin vertical colored sand layers were placed at intervals of approximately $10 \mathrm{~mm}$ in the model ground adjacent to the glass wall on the side of the soil chamber. The ground deformation while pulling the anchor model was recorded through the glass wall with a CCD camera.

\subsection{DEM simulation}

A modified version of granular LAMMPS software was used for three-dimensional DEM simulations.

Three rigid planar surfaces were used to simulate the side walls in the $\mathrm{X}$ direction and the bottom wall of the soil chamber, while two periodic boundaries were placed in the Y-direction (Figure $2 b$ ).

A simplified Hertz-Mindlin contact model was adopted to calculate interactions between the soil particles, between the soil particle and the anchor body, and between the soil particle and the rigid wall. A particle shear modulus of $29.1 \mathrm{GPa}$, Poisson's ratio of 0.23 and particle density of $2,640 \mathrm{~kg} / \mathrm{m}^{3}$ were used. Referring to Table 1, the inter-particle friction coefficient $(f)$ during pulling was 0.5 for spherical particles, and $0.01,0.1,0.3$ and 0.5 for R2 particles.

In the simulations, two types of particle shape were used (Figures $2 \mathrm{c}$ and 2d): spherical particle, and clumped two particles (referred to here as R2). A R2 particle consisted of two spherical particles that were rigidly connected, and the volume of a R2 particle consisting of two smaller spheres (Figure 2d) was adjusted to that of the original spherical particle (Figure 2c). Two spherical particles that constitute a $\mathrm{R} 2$ particle were prohibited from relative translation and rotation at the connected point. Thomas and Bray [9] adopted R2 in their 2D simulation and modelled an uplift of a horizontal anchor plate. They observed that the displacement pattern was similar to typical experimental results.

The anchor body was modelled as a rigid box consisting of six rigid walls having a height of $27 \mathrm{~mm}$ where the same material properties with the spheres were used. According to Palmeria [10], the normalised bearing strength becomes independent of the soil grain size if the size ratio between the thickness of object moving in the ground (i.e. the anchor body) and the average grain diameter exceeds twelve. The simulation configuration adopted in this study had the size ratio of the anchor body thickness to the average grain size was almost fourteen. Therefore, undesirable effects due to size dependence on the interaction between the particle and the anchor body may be avoided. The conditions of the centrifugal model tests and DEM analyses are summarized in Table 1.

Particles were generated randomly above the base wall having an initial void ratio of about 3, and then gravitational forces were applied to the particles with a $f$ value of 0.001 for R2 and 0.08 for spherical particle adopting a damping. Particle kinetic energy was removed by applying an additional damping after the particles settled on the base wall. The f value was increased to 0.01 , 0.1 or 0.5 as shown in Table 1. After that, the mass of the soil particles was increased to 30 times the original mass in order to reproduce the stress field corresponding to the centrifugal acceleration of $30 \mathrm{G}$. The resultant void ratio was around 0.655 where a slightly looser packing was obtained compared to the centrifugal model tests. For the

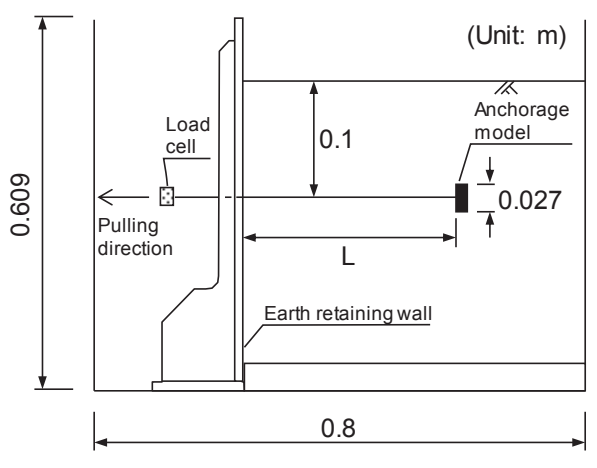

a) Test setup of a centrifugal model test.

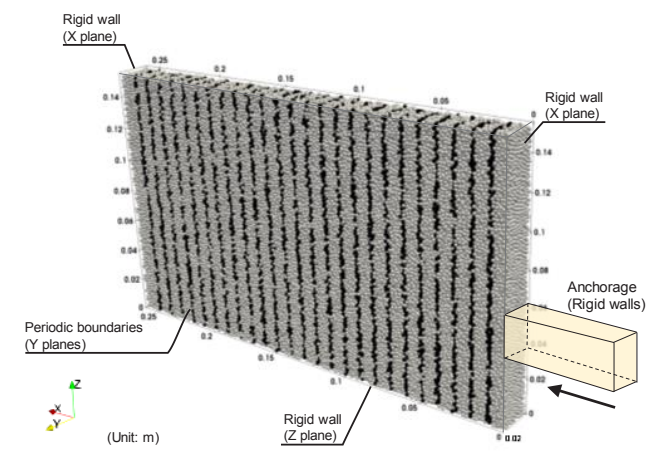

b) Test model by DEM $(\mathrm{L}=260 \mathrm{~mm})$.

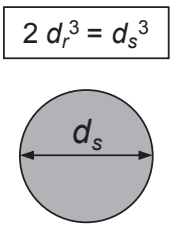

c) Spherical particle.

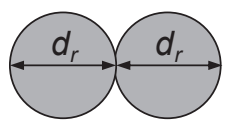

d) Rigid particle (R2).

Fig. 2. Test setup and DEM model. 
Table 1. Condition of centrifugal model tests and DEM simulations.

\begin{tabular}{|c|c|c|c|c|c|c|}
\hline & Outline & Material / Particle & Particle size & $e$ & $f$ & $L(\mathrm{~m})$ \\
\hline Test 1 & $\begin{array}{l}\text { Observation of ground deformation } \\
\text { through glass wall of soil chamber }\end{array}$ & \multirow[t]{2}{*}{ Toyoura sand } & \multirow[t]{2}{*}{$D_{50}=0.2 \mathrm{~mm}$} & 0.613 & - & $0.25(7.5)$ \\
\hline Test 2 & Circular anchor plate in 3-dimension & & & 0.621 & - & $0.33(10.0)$ \\
\hline \multirow{6}{*}{ DEM } & \multirow{6}{*}{ Plane strain condition } & \multirow{3}{*}{ R2 particle } & \multirow{3}{*}{$2 d_{r}=3.17 \mathrm{~mm}$} & \multirow{3}{*}{0.657} & 0.01 & \multirow{3}{*}{$0.26(7.8)$} \\
\hline & & & & & 0.1 & \\
\hline & & & & & 0.5 & \\
\hline & & \multirow{3}{*}{ Spherical particle } & \multirow{3}{*}{$d_{s}=2.00 \mathrm{~mm}$} & \multirow{3}{*}{0.654} & \multirow{3}{*}{0.5} & $0.25(7.5)$ \\
\hline & & & & & & $0.13(4.0)$ \\
\hline & & & & & & $0.067(2.0)$ \\
\hline
\end{tabular}

$e$ : void ratio, $f$ : inter-particle friction coefficient, $L$ : distance from anchor body to wall on opposite side

The value in parentheses in the column of $L$ is the length corresponding to the actual scale converted at the centrifugal acceleration field of $30 \mathrm{G}$

R2 packing, the 2nd-order fabric (contact) tensor was $0.306,0.306$ and 0.387 in the $\mathrm{X}, \mathrm{Y}$ and $\mathrm{Z}$ axis direction, respectively. Once the sample had reached a quasi-static equilibrium, a pull-out velocity of $1 \mathrm{~mm} / \mathrm{s}$ was imposed to anchorage. For the pull-out stage, the damping coefficient was increased to 0.1 . In order to reduce calculation costs, the pulling speed in the simulation was set to 20 times the pulling speed in the centrifugal model tests; it was confirmed that a quasi-static condition was satisfied by using the velocity through parametric simulation on pullout velocity. The earth pressures exerted on the wall on the opposite side of the anchorage were measured with an interval of $10 \mathrm{~mm}$.

Referring to Table 1, the distance from the anchor body to the side wall on opposite side $L$ was set to about 2.5 times the burial depth under the condition so that the pull-out behaviour is not affected by the wall. For spherical particles, the $L$ values were $0.067 \mathrm{~m}, 0.13 \mathrm{~m}$, and $0.25 \mathrm{~m}$ corresponding to $0.67,1.3$ and 2.5 times the burial depth, respectively.

\section{Results}

\subsection{Effect of particle shape}

\subsubsection{Pull-out force - displacement}

Figure 3 shows the development of pull-out force for Test 1 and DEM simulations. The pull-out force in DEM simulation was calculated by summing the contact forces between the anchor body and the soil particles. The pullout forces obtained in Test 1 and DEM simulations were normalized by Equation 1a. However, in order to compare with the DEM simulation results, the forces obtained in Test 2 were normalized by Equation $1 b$ in consideration of shape factor [1] for conversion from three dimensions condition to plane strain condition.

$$
\begin{gathered}
P_{\text {norm }}=P /(A \gamma D / 2) \\
P_{\text {norm }}=P /\left(C_{S} A \gamma D / 2\right)
\end{gathered}
$$

where, $P$ is the pull-out force, $A$ is the bearing area of anchor body, $\gamma$ is the unit weight of soil, $D$ is the diameter or height of anchor body and $C_{S}$ is the shape factor of 6.4

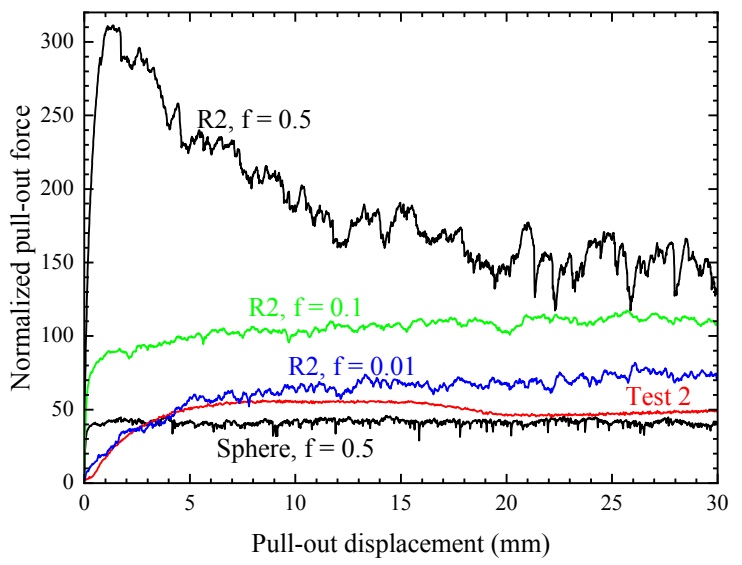

Fig. 3. Pull-out load against displacement.

[1]. The pull-out load of R2 with $f$ of 0.01 and spherical particle with $f$ of 0.5 were similar to the test result. Especially, R2 with $f$ of 0.01 agreed very well in the range up to about $5 \mathrm{~mm}$ displacement. For R2 with $f$ of 0.5 , a sharp peak appeared in the pull-out load at a small displacement. Compared to spherical particles, the pullout load of R2 was larger. This indicates that the particleinterlocking caused by the non-spherical shape as well as the inter-particle friction greatly affected the pull-out load.

\subsubsection{Ground deformation}

Figure 4 is indicative of the displaced location of the ground in Test 1 where the ground deformation before and during pulling are overlapped. A wedge-shaped area with displacement concentrated was formed in front of the bearing surface. And a shear plane with an angle of $53^{\circ}$ to the horizontal was generated from the tip of the wedge and the upwards displacement in the area above the wedge was noticeably large. Figure 5 shows the calculated particle displacement vector by DEM with the shear planes obtained from Test 1 also displayed (in broken lines). The displacement of the spherical particles was very similar to that of Test 1 (Figure 5a) except occurrence of the clear shear plane. For R2 with an $f$ value of 0.5 , although roughly the deformation characteristics were similar to that of Test 1 , a wider range of particles were displaced during pulling than Test 1 (Figure 5b). For R2 with $f$ values of 0.1 and 0.01 , the particles were 
displaced radially in front of the anchor plate, while a clear upwards displacement was not observed (Figures $5 \mathrm{c}$ and $5 \mathrm{~d}$ ). Particles with a small $f$ value are less likely to exhibit positive volumetric dilation during shearing [11], which has a considerable influence on the displacement pattern due to pulling to the horizontal direction.

\subsubsection{Angular velocity distribution}

Figure 6 shows the distribution of particle angular velocity around the Y-axis (see Fig. 2b) with the shear planes obtained from Test 1 (broken lines). The intense shear zone annotated in Figure 6a corresponds to the zone with larger angular velocity. For spherical particle, a shear zone approximately $0.04 \mathrm{~m}$ in width was observed along the slip line obtained in Test 1 , and the width was equivalent to 20 times the particle diameter. For R2 with $f$ of 0.5 , a wider zone of large particle angular velocity was observed compared to spherical particle (Figure 6b).

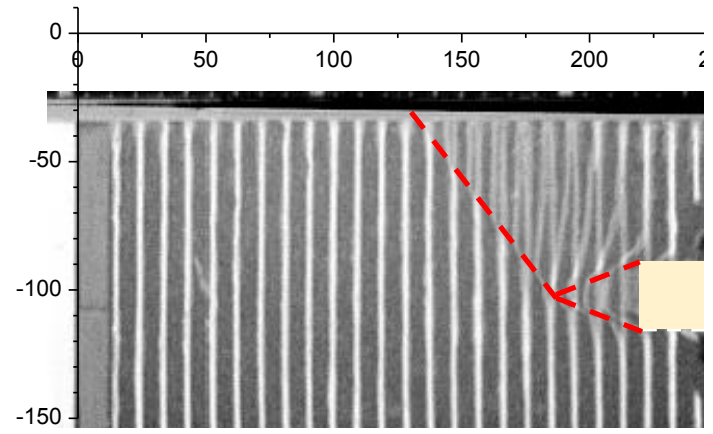

Fig. 4. Ground deformation of Test 1.

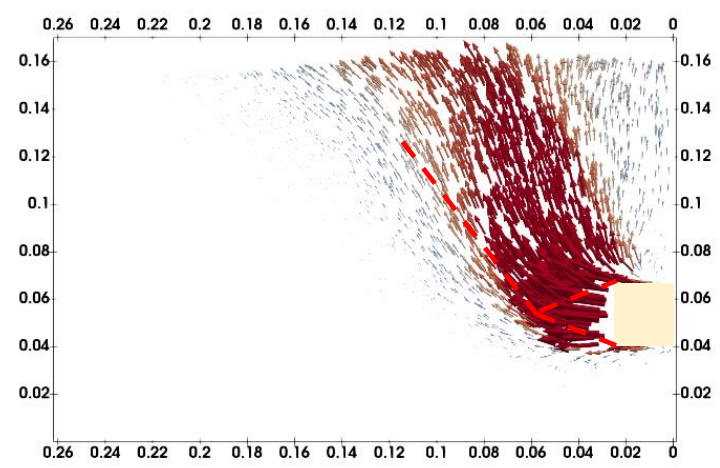

a) Spherical particle, $f=0.5$

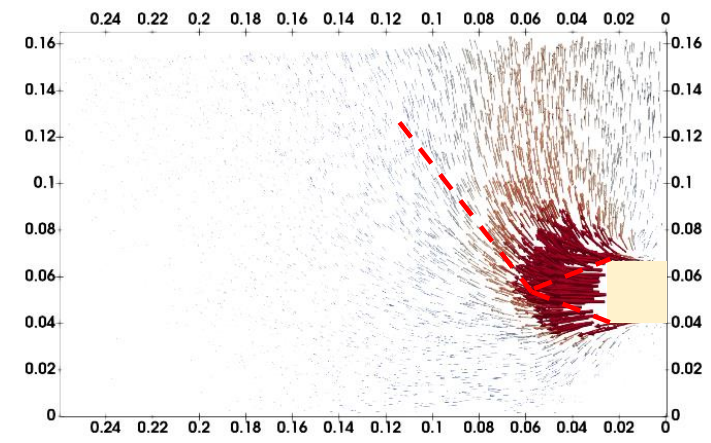

c) $\mathrm{R} 2, f=0.1$
According to Ueno et al. [12], the width of shear zone depends on the grain shape, where the width of shear band for glass beads is almost 20 times the mean diameter $D_{50}$. This trend corresponded to the result of DEM analysis in the case of spherical particle.

\subsection{Effect of distance from anchor body to wall}

\subsubsection{Pull-out force and ground deformation}

Figure 7 shows the development of pull-out force for $L$ of $0.067,0.13$ and $0.25 \mathrm{~m}$ where spherical particles were used. The pull-out force did not change significantly. Because the immovable rigid wall on the opposite side of the anchor body provided an excessive reaction force for the anchor to obtain the pull-out resistance, and when a deformable and movable retaining wall: steel sheet pile is used, such the excessive reaction force is not introduced. Figures $5 \mathrm{a}$ and 8 show the particle displacement vector at a pull-out displacement of $25 \mathrm{~mm}$. When $L$ is shorter (i.e. 0.13 and $0.067 \mathrm{~m}$ ), the wall restricted the horizontal movement of particles compared with the result on $L$ of $0.24 \mathrm{~m}$. Referring to Figure 8, the upward movement of particles is dominant particularly for $L$ of $0.067 \mathrm{~m}$; most of the particles located higher than the anchor body were displaced upwards. It is evident from the simulation results that a conventional theory cannot be applied to the anchor system having a short distance from the wall. Furthermore, according to the design code on conventional anchorages, it is necessary for the anchor body to be located from a wall by $4 \mathrm{~m}(0.13 \mathrm{~m}$ on the model scale) or more. However, for expanded-diameter

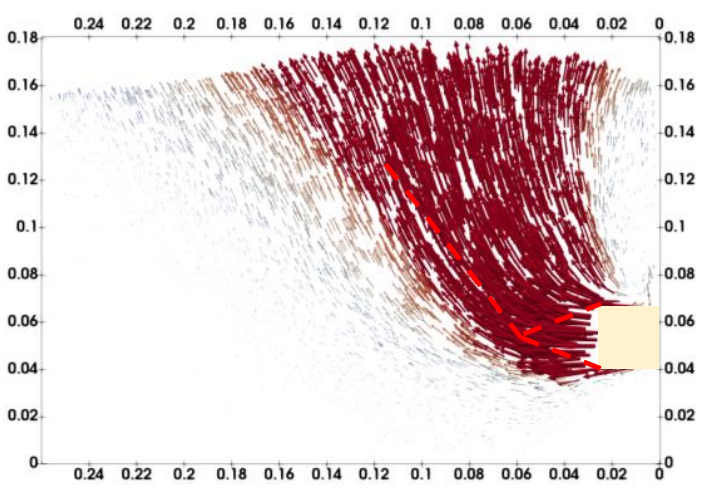

b) $\mathrm{R} 2, f=0.5$

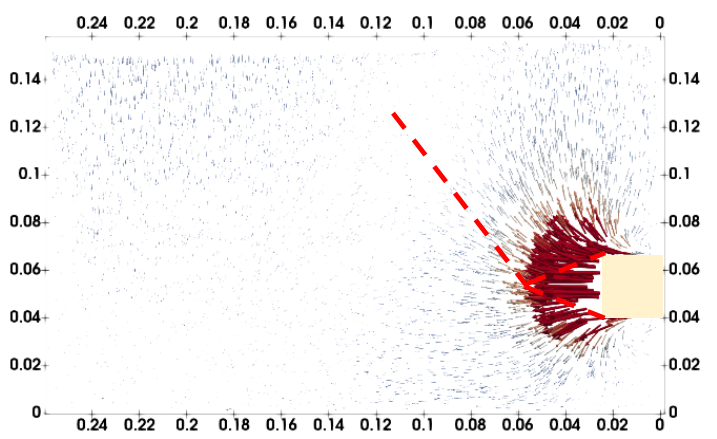

d) $\mathrm{R} 2, f=0.01$

Fig. 5. Calculated particle displacement vector at $25 \mathrm{~mm}$ pull-out displacement (slip lines obtained in Test 1 display in broken line). 


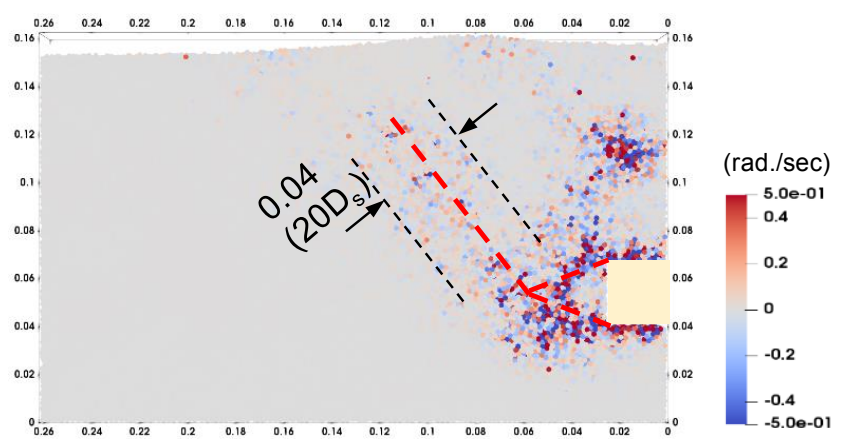

a) Spherical particle, $f=0.5$

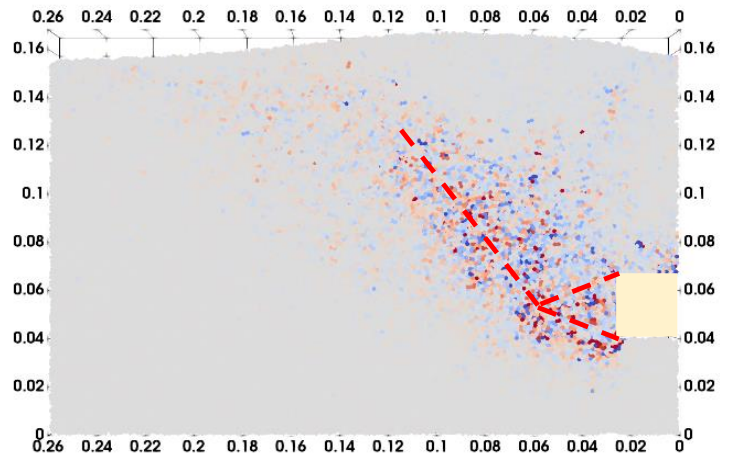

b) $\mathrm{R} 2, f=0.5$

Fig. 6. Particle angular velocity distribution of spherical particles and rigid particles at pull-out displacement of $25 \mathrm{~mm}$.

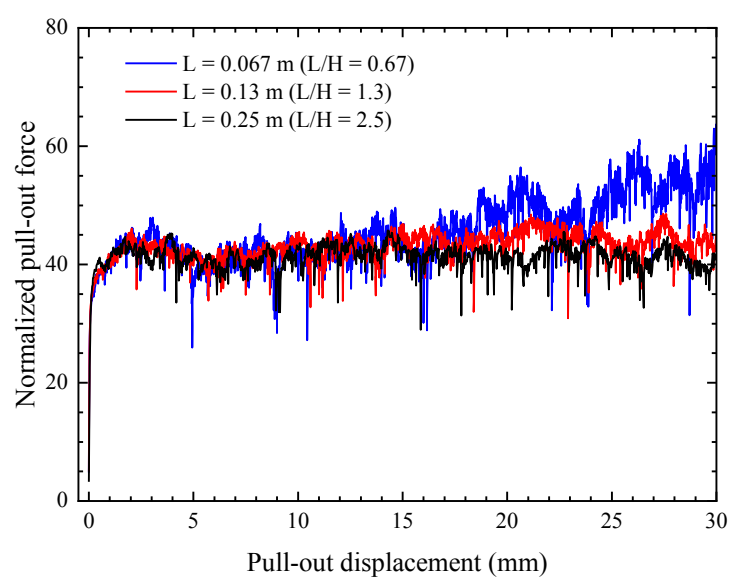

Fig. 7. Pull-out load against displacement (spherical particle with $\mathrm{L}$ of $0.067 \mathrm{~m}, 0.13 \mathrm{~m}$ and $0.25 \mathrm{~m}$ ).

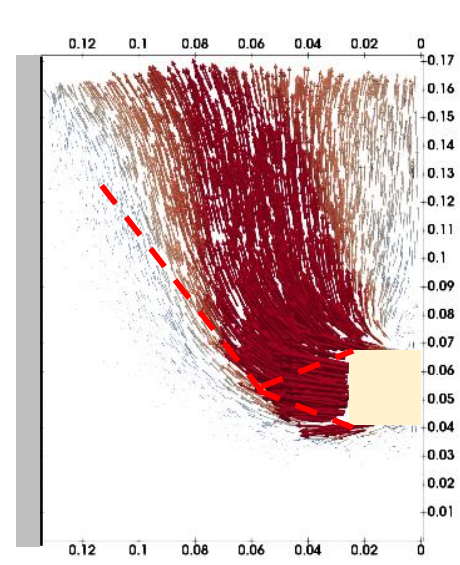

a) $\mathrm{L}$ of $0.13 \mathrm{~m}$

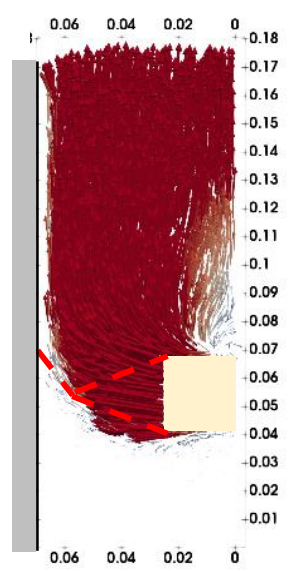

b) $\mathrm{L}$ of $0.067 \mathrm{~m}$
Fig. 8. Calculated particle displacement vector at $25 \mathrm{~mm}$ pullout displacement.

anchorages, the distance of $4 \mathrm{~m}$ may not be sufficient depending on the condition such as deeper anchorage. For diameter-expanded anchorage, evaluating a threshold of distance depending on the burial depth is important.

\subsubsection{Strong contact force and earth pressure}

To discuss the particle-scale response associated with pull-out, strong contact forces (top 3\% of contact force), connecting the centres of contacting particles were extracted from DEM data as illustrated in Figure 9. As the contact force increases with the burial depth, the contact forces plotted in Figure 9 are normalised by the depth of the contact point from the ground surface. Earth pressure and frictional stress distributions along the side wall are also shown in Figure 9 The earth pressure and frictional stress were calculated by summing contact forces acting on the wall at every height of $10 \mathrm{~mm}$.

For $L$ of $0.25 \mathrm{~m}$, strong contact forces were observed in the wedge-shaped area, and radially distributed area outside the wedged-shaped area. The steepest radially distributed strong contact forces were observed along the slip line obtained in Test 1 . The strong contact force distribution did not vary much despite the distance between the wall and the anchor. Because the wall was modelled as a fixed boundary in the simulation, an excessive reaction force corresponding to the pull-out force was obtained from the wall in the case of smaller $L$. The closer the wall to the anchor body, the greater the earth pressure and frictional stress exerting on the wall and the depth of the peak changed.

\section{Conclusions}

The following main conclusions can be drawn from the results presented in this paper:

1) Compared to spherical particles, a wider range of ground was affected when R2 particles are used due to interlocking between R2 particles. R2 cases exhibited larger pull-out resistance than spherical particle where larger $f$ gave greater pull-out resistance.

2) The simulation of spherical particle for $f$ of 0.5 most closely agreed with displacement field and pull-out load of the centrifugal model test result. Although a narrow shear zone like that obtained in the test was not observed, the particle rotation was outstanding in the area of the width of about 20 particles.

3) When the anchor body was far enough from the wall, a wedge-shaped zone was generated in front of the anchor body, strong contact forces observed in the wedge-shaped zone. They were radially distributed at the outside of the wedge-shaped zone. This situation was maintained during pulling.

4) The closer the distance from the anchor body to the retaining wall, the greater the upward ground displacement and the greater the earth pressure exerting on the retaining wall due to pull-out. Thus 


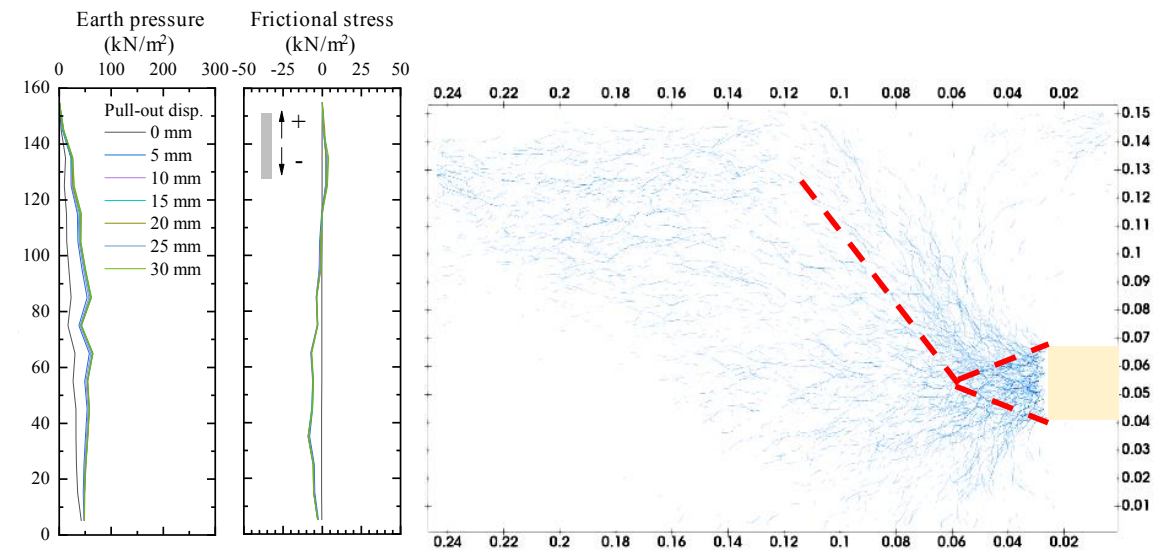

a) $\mathrm{L}$ of $0.25 \mathrm{~m}$

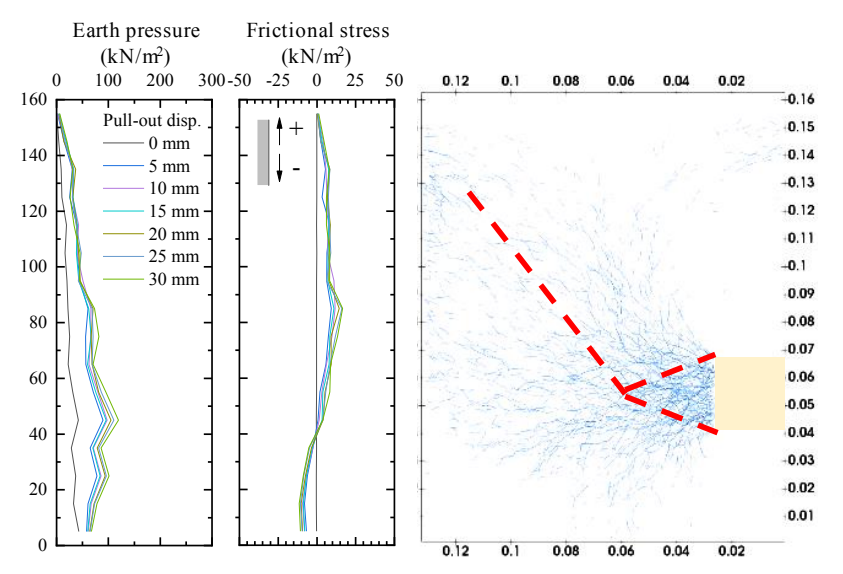

b) $\mathrm{L}$ of $0.13 \mathrm{~m}$

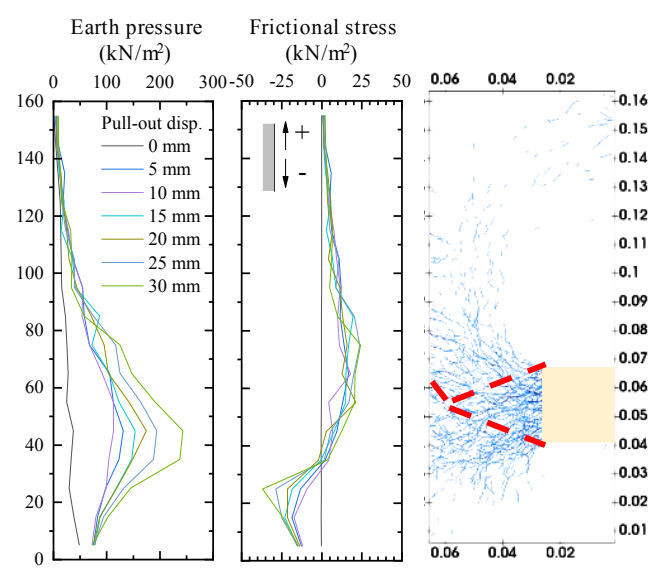

c) $\mathrm{L}$ of $0.067 \mathrm{~m}$

Fig. 9. Earth pressure and frictional stress on the wall opposite to the anchor body for spherical particle, and strong contact force distribution at $25 \mathrm{~mm}$ pull-out displacement.

the design method of pull-out resistance needs to consider the presence of the retaining wall.

5) A conventional theory of failure mechanism associated with diameter-expanded anchor cannot be applied if the lateral distance between the anchor and the retaining wall is shorter than a threshold distance depending on the burial depth.

A part of this research was based on the Oakforest-PACS system operated at The Joint Centre for Advanced HPC (JCAHPC) under cooperation with the Information Technology Centre at the University of Tokyo and the Centre for Computational Sciences at the University of Tsukuba. The modified LAMMPS code used here was developed by Dr. Kevin J. Hanley, The University of Edinburgh.

\section{References}

1. T. Sawamatsu, H. Kohashi, Y. Udagawa, S. Kobayashi, T. Hayashi, K. Okazaki, JSCE J. Geotech. \& Geoenv. Eng., 66, (2010) (In Japanese)

2. A. Balla, Proc. 5th Int. Conf. Soil Mech. \& Fnd. Eng. (1961)

3. G.G. Meyerhof, Proc. 8th Int. Conf. Soil Mech \& Fnd., 2 (1973)

4. N.K. Ovesen, Int. Conf. on SMEE, 10 (1981)
5. Dickin Edward A., J. Geotech. Eng,. 114 (1988)

6. H.B. Sutherland, Conf. on SMFE, 4 (1965)

7. R.K. Rowe, E.H. Davis, Géotechnique, 32 (1982)

8. R.S. Merifield, S.W. Sloan, Can. Geotech. J., 43 (2006)

9. Thomas Patricia A., Bray Jonathan D., J. Geotech. \& Geoenv. Eng., 125 (1999)

10. E.M. Palmeira, Geotextiles \& Geomembranes. 27, (2009)

11. G. Yan, H. Yu, G. McDowell, Procedia Earth \& Planetary Science., 1 (2009)

12. K. Ueno, K. Miura, A. Tanise, K. Maeda, Proc. Jpn Conf. Geotech. Eng., 26 (1991) (In Japanese) 